\title{
Visual orientation during and after lateral head, body, and trunk tilt'
}

\author{
N. J. WADE \\ MONASH UNIVERSITY
}

Visual judgments of orientation were investigated during (effect) and after (aftereffect) different body postures. In Experiment 1 four trained Ss made apparent verticality (AV) judgments before and after $2 \mathrm{~min}$ in each of seven orientations: head tilt left and right, body tilt left and right, trunk tilt left and right and a control condition with head and body upright. The aftereffect was significant for all postures excepting trunk tilt left and the control. The aftereffect from head tilt was greater than that from the same degree of body tilt, and that in the trunk tilt condition was in the same direction as predicted from neck stimulation. In Experiment 2, 30 Ss made AV judgments during tilt in the same seven postures. The E-phenomenon resulted from both head and body tilts, and an effect was found for trunk tilt in the direction predicted from neck stimulation. The results are discussed in terms of the otolith, neck, and trunk receptor systems.

With the body upright a line of light in an otherwise dark or featureless environment can be accurately adjusted to the vertical (Mann, Berthelot-Berry, \& Dauterive, 1949; Neal, 1926). Tilting the body laterally relative to gravity displaces the apparent vertical (Aubert, 1861; Müller, 1916). The extent and direction of displacement is a function of the extent and direction of body tilt (Bauermeister, 1964; Fischer, 1927, 1930; Miller, Fregly, van den Brink, \& Graybiel, 1965; Schöne, 1964). For body tilts less than about $60^{\circ}$ the apparent vertical (AV) is located on the opposite side of the gravitational vertical (GV) to that of tilt so that a GV line appears tilted in the same direction as tilt, an effect called the E-phenomenon. Greater degrees of lateral body tilt result in displacement of the $\mathrm{AV}$ to the same side of $\mathrm{GV}$ as tilt so that a GV line appears tilted in the opposite direction to tilt, an effect referred to as the A-phenomenon.

Displacement of AV also occurs with the head upright immediately following a period of 2 or 3 min head tilt with eyes closed (Day \& Wade, 1966). Posttilt AV is shifted in the direction of prior tilt relative to pretilt judgments. For lateral head tilt within the range of $40^{\circ}$ of GV this visual spatial aftereffect is in the opposite direction to the visual effect during tilt.

The E- and A-phenomena can be interpreted as instances of perceptual constancy. When the body is tilted $30^{\circ}$ right then, allowing for about $5^{\circ}$ of ocular countertorsion (Miller, 1962; Miller \&
Graybiel, 1963; Schöne, 1962), the retinal image of a GV object is tilted about $25^{\circ}$ counterclockwise (CCW) relative to the normal retinal meridian of the eye. Despite this CCW displacement of the image, the GV object is judged to be tilted about $4^{\circ}$ clockwise (CW). Therefore AV would be located about $4^{\circ} \mathrm{CCW}$, an instance of overconstancy of visual orientation. Similarly, the A-phenomenon can be considered as underconstancy of object orientation. The visual projection is equivocal since its orientation is jointly determined by both object tilt and body tilt. To resolve perceptually this ambiguity, information for body tilt is necessary. It is considered that this information is provided by stimulation of the otolith structures of the utricle and by joint, muscle, tactile, and visceral receptors.

The visual aftereffect following head and body tilt can be interpreted as a change in visual orientation constancy mediated by stimulation-induced modifications of the sensory systems providing information about body position.

The purpose of the experiments reported here was to investigate the relative contributions of the otolith, neck, and trunk receptor systems to the visual effect and aftereffect consequent on lateral tilt. This has been achieved by using different tilt postures designed to involve these systems in different combinations.

\section{EXPERIMENT 1}

It is possible, using certain body orientations, to stimulate the three receptor systems providing postural information in pairs. Head tilt (HT) alone results in stimulation of the otolith and neck receptors. Body tilt (BT) to the same degree stimulates the otolith system similarly but with the involvement of the trunk receptors. Maintaining the head upright and tilting the trunk (TT) produces neck and trunk stimulation. Visual aftereffects following prolonged stimulation in these postures should yield data suggestive of the mechanisms involved in both the aftereffect and orientation generally. In the following experiment AV judgments were made before and after $2 \mathrm{~min}$ in the above postures together with a control condition in which the body remained upright.

\section{Method}

Apparatus. Body orientations were effected by means of a rectangular box, open on one side, 196 $\mathrm{cm}$ high, $51 \mathrm{~cm}$ wide, and $60 \mathrm{~cm}$ deep, which could 
be rotated about a horizontal axis approximately through its center of gravity and locked into position at any angle. Adjustable leg, hip, and shoulder supports minimized any body movement during lateral tilt. Head position was controlled by individual dental-composition bite boards, which could be rotated independently of the box in the same (frontal) plane and locked at any angle. The bite board system was fixed to a crossbar attached by nuts to two tubes projecting from a heavy adjustable steel plate inside and at the back of the box. The orientation of the bite board and box could be measured to the nearest $0.25^{\circ}$ by means of protractor scales. As the steel plate and the base of the box were adjustable in height, $S$ was so positioned that the axis of rotation was approximately through his center of gravity. Thus by rotating the box and bite board independently, the body postures BT, HT, and TT could be achieved.

The visual stimulus object was a line $78 \mathrm{~mm}$ long and $0.3 \mathrm{~mm}$ wide corresponding to an aperture in an otherwise light-tight lamp housing, $120 \mathrm{~cm}$ from S's eyes and with an intensity of $0.04 \mathrm{~mL}$. The line rotated frontoparallel to $S$ with its center in the median plane and adjustable to eye level. The orientation of the line, which could be measured to the nearest $0.1^{\circ}$, was controlled either by $\mathrm{S}$ using a switch activating a synchronous $1 \mathrm{rpm}$ reversible motor or manually by $\mathrm{E}$. The whole light-motor arrangement was fixed to the box so that its position relative to $S$ remained unchanged during tilt. The apparatus was housed in a darkroom.

Subjects. Four Ss, three male and one female, well trained in making verticality judgments, took part in this experiment.

Procedure. A trial consisted of four adjustments of the line to $\mathrm{AV}$, two each from starting positions of $10^{\circ} \mathrm{CW}(+)$ and $10^{\circ} \mathrm{CCW}(-)$ of GV, with body upright. The box and bite board were then adjusted to the appropriate orientation, and $S$ remained in that position for $2 \mathrm{~min}$, after which he was returned to the normal upright posture and required to adjust the line to $A V$ from the first of the pretilt starting positions. Fine adjustment of the line (bracketing) was permitted. Eyes were closed at all times other than when making an adjustment. The difference between the posttilt adjustment and the mean of the pretilt adjustments was the measure of the visual aftereffect. The seven body orientations studied were HT $30^{\circ}$ right (R) and $30^{\circ}$ left (L), BT $30^{\circ} \mathrm{R}$ and $30^{\circ} \mathrm{L}, \quad \mathrm{TT} 30^{\circ} \mathrm{R}$ and $30^{\circ} \mathrm{L}$, and the control condition with body upright. A block consisted of one trial in each orientation presented in a different random order for each $\mathrm{S}$. The intertrial interval was $3 \mathrm{~min}$ to ensure dissipation of the aftereffect (Wade \& Day, in press). Four blocks were given to each $S$, the order of postures varying from block to block with at least one day between each.
Table 1 Means (degrees) and Variances of Aftereffect (Experiment 1) and Effect (Experiment 2) for Head, Body, and Trunk Tilt.

Body Orientation

\begin{tabular}{llrrrrrrrr} 
Experiment & & L HT & R HT & L BT & R BT & L TT & R T T Control \\
\hline Exp. 1. & $\bar{X}$ & -2.10 & +1.46 & -1.37 & +0.76 & +0.66 & -0.96 & +0.08 \\
Aftereffect & $S^{2}$ & 0.63 & 0.16 & 0.60 & 0.06 & 0.13 & 0.12 & 0.04 \\
Exp. 2. & $\bar{X}$ & +4.71 & -4.08 & +3.40 & -3.73 & -0.94 & +1.37 & +0.28 \\
Effect & $S^{2}$ & 19.38 & 14.78 & 21.00 & 15.36 & 4.96 & 5.69 & 2.54
\end{tabular}

Note: + denotes $\mathrm{CW}$ deviation from $\mathrm{GV}$; - denotes $\mathrm{CCW}$ deviation.

Design. The contrasts (comparisons) between the means were planned before collection of the data. Pre- and posttest measures were obtained for each of the seven postures, making 14 means in all. Nine contrasts were planned from the 14 means. Seven contrasts concerned pre- and posttest differences (aftereffects) for each posture, and two concerned the interrelations of the aftereffects from HT, BT, and TT. The contrasts can be expressed in the following ways:

Contrast 1- L HT pre- and posttests do not differ; Contrast 2- R HT pre- and posttests do not differ; Contrast 3- L BT pre- and posttests do not differ; Contrast 4- R BT pre- and posttests do not differ; Contrast 5- L TT pre- and posttests do not differ; Contrast 6- R TT pre- and posttests do not differ; Contrast 7- pre- and posttests for the control do not differ;

Contrast 8- the aftereffect from the L HT plus that from $R$ BT will not differ from the aftereffect following $R$ TT;

Contrast 9- the aftereffect from R HT plus that from $L$ BT will not differ from the aftereffect following $\mathrm{L}$ TT.

\section{Results}

Means (degrees) and variances for the aftereffect are given in Table 1. Aftereffects generated by prolonged HT are greater than those from the corresponding BT, and TT-produced aftereffects are in the direction opposite to previous tilt.

The summary of the statistical analysis is given in Table 2. The predictions were tested by the method of planned contrasts (Hays, 1964; Rodger, 1965). The error term was the subject-orientation interaction. The null hypothesis was rejected for Contrasts $1,2,3,4$, and 6 , and accepted for Contrasts $5,7,8$, and 9 ; i.e., pretests differed significantly from posttests for all conditions other than L TT and the control (body upright), and the aftereffect combinations of $\mathrm{L} H \mathrm{HT}+\mathrm{R}$ BT and R HT + L BT were not significantly different from $R T T$ and $\mathrm{L} T \mathrm{~T}$, respectively.

\section{EXPEAIMENT 2}

Constancy of visual orientation judgments was affected by prolonged stimulation in the above pos- 
tures. Obtaining $\mathrm{AV}$ judgments during tilt in the same seven postures should provide further evidence concerning the relative importance of the otolith, neck, and trunk systems in mediating this visual orientation constancy.

\section{Method}

Apparatus. The apparatus was the same as that used in Experiment 1.

Subjects. Thirty Ss, 13 males and 17 females from an introductory course in psychology, participated.

Procedure. The same seven body orientations were studied as in Experiment 1. A trial involved $S$ adjusting the line to $\mathrm{AV}$ during tilt while in one of the seven postures. Starting positions of the line were $+10^{\circ}$ and $-10^{\circ}$ of GV. The S underwent 14 trials, one from each of the starting positions while tilted in each of the seven postures, in random order. The intertrial interval was $30 \mathrm{sec}$, during which $\mathrm{S}$ was in the normal upright posture. The S's eyes were closed at all times other than when making an adjustment.

Design. Six contrasts were planned concerning the seven treatment means:

Contrast 1- AV judgments made with L HT do not differ from those with body upright control);

Contrast 2- AV judgments with R HT do not differ from control;

Contrast 3- AV judgments with L BT do not differ from control;

Contrast 4- AV judgments with R BT do not differ from control;

Contrast 5- AV judgments with L TT do not differ from control;

Contrast 6- AV judgments with R TT do not differ from control.

\section{Results}

The mean AV judgments (in degrees relative to GV) are shown in Table 1 together with the vari-

Table 2. Analysis of the Aftereffect Data by the Method of Planned Contrasts.

\begin{tabular}{clccc} 
& Source & df & MS & F \\
\hline Contrast & & & & \\
1 & L HT & 1 & 8.820 & $32.189 *$ \\
2 & R HT & 1 & 4.246 & $15.496^{*}$ \\
3 & L B & 1 & 3.428 & $12.511^{*}$ \\
4 & $\mathrm{R} \mathrm{BT}$ & 1 & 1.146 & $4.182^{*}$ \\
5 & $\mathrm{~L} \mathrm{TT}$ & 1 & 0.871 & 3.179 \\
6 & $\mathrm{R} \mathrm{TT}$ & 1 & 1.866 & $6.810^{*}$ \\
7 & Control & 1 & 0.010 & 0.036 \\
8 & $\mathrm{~L} \mathrm{HT}+\mathrm{R} \mathrm{BT}=\mathrm{R} \mathrm{TT}$ & 1 & 0.099 & 0.361 \\
9 & $\mathrm{R} \mathrm{HT}+\mathrm{L} \mathrm{BT}=\mathrm{L} \mathrm{TT}$ & 1 & 0.174 & 0.635 \\
Remainder & & 4 & 4.074 & $14.369 *$ \\
Error & & 39 & 0.274 & \\
\hline
\end{tabular}

$* p<.05$
Table 3. Z-Scores Derived from the Wilcoxon Matched-Pairs Signed-Ranks Test for the Six Comparisons and the Decisions.

Comparison

\begin{tabular}{clllllll} 
with control & LHT & R HT & L BT & R BT & L TT & R TT \\
\hline Z & -5.531 & -5.142 & -4.733 & -4.469 & -4.165 & -3.434
\end{tabular}

Decision Reject Reject Reject Reject Reject Reject

ances. AV judgments with HT are displaced further in the direction opposite to tilt than those with the corresponding BT. Judgments during TT were in the same direction as tilt. Variances for the conditions in which the head was nonvertical were greater than those with the head vertical (L TT, R TT, and control). The hypothesis of homogeneity of variance was rejected using Hartley's test (Winer, 1962) which gave $F \max =8.728$ ( $d f=7 / 29, p<.01)$. Therefore the nonparametric Wilcoxon matched-pairs signed-ranks test was applied (Siegel, 1956) yielding $z$-scores for all contrasts. The null hypothesis is rejected for $z>1.96$ with a type $I$ error rate of .05 . Table 3 gives the results of the analysis; AVs for all tilt conditions differed significantly from the AV with head upright $(p<.05)$.

\section{DISCUSSION}

The method of adjustment with bracketing was used in both experiments since bracketing reduces starting position effects (O'Connell, Lathrop, Weintraub, \& McHale, 1967). However, in Experiment 1 this increased the time lapse between initiation and completion of the posttest, and as dissipation of the aftereffect is most rapid immediately following stimulation (Wade \& Day, in press), the magnitudes of the aftereffects would be slightly reduced. This dissipation may explain the nonsignificant L TT aftereffect.

Considering postural orientation mechanisms in terms of otolith (o), neck (n), and trunk (t) systems and stimulating these in pairs provides data suggestive of the relative contributions of each system to the visual effect during tilt and the aftereffect which follows it. A similar approach was used by Mittelstaedt (1964) in studying the gravitational orientation responses of the pigeon.

The postures employed in the present experiments can be considered as stimulating the $o, n$, and $t$ systems in the following manner:
$\mathrm{R} H \mathrm{H}=+\mathrm{O}+\mathrm{n}$
$\mathrm{L}$ HT $=-0-\mathrm{n}$
$\mathrm{R} B \mathrm{BT}=+0+\mathrm{t}$
$\mathrm{L} B \mathrm{BT}=-0-\mathrm{t}$
$\mathbf{R} \mathbf{T T}=-\mathrm{n}+\mathrm{t}$
$\mathrm{L} T \mathrm{TT}=+\mathrm{n}-\mathrm{t}$

Since all conditions involve $30^{\circ}$ tilt, $R$ TT involves an $\mathrm{n}$ component equivalent to $\mathrm{L} H \mathrm{HT}$ and a $\mathrm{t}$ component as in R BT. Similarly $L$ TT has $n$ as in R HT 
and $t$ as in $L$ BT. An aftereffect was produced by stimulation in $\mathrm{TT}$, and this was most probably due to adaptation of the $n$ or $t$ systems, or both. Although HT and BT in the same direction stimulate the o system by the same amount, the magnitudes of the aftereffects following them differ. Therefore the $n$ and $t$ systems are adapted together with, or in place of, the $o$ system to produce the aftereffect from HT and BT. The aftereffect from HT is larger than that from BT so that the contribution of the $n$ system is greater than that of the $t$ system. For a condition where $n$ and $t$ are put into opposition an aftereffect in the direction produced by $\mathrm{n}$ stimulation would be expected, with magnitude approximately equal to the algebraic sum (or arithmetic difference) of those from HT and BT. The TT condition fulfills these requirements since the $n$ and $t$ components are in opposition. Further, the algebraic sum of HT and the opposite BT results in similar stimulation:

$$
\begin{aligned}
\text { R TT } & =-n+t \\
\text { L HT + R BT } & =-0-n+0+t \\
& =-n+t \\
\therefore \quad \text { L HT + R BT } & =\text { R TT }
\end{aligned}
$$

Each TT-produced aftereffect was in the direction expected from $n$ stimulation and was not significantly different from the algebraic sum of the appropriate HT and BT aftereffects.

It is probable that the aftereffects produced by all tilt conditions result from $n$ and $t$ adaptation since there is no adaptive change in the oculogravic illusion with prolonged rotation (Clark \& Graybiel, $1962,1966 \mathrm{~b})$. The oculogravic illusion is believed to be an index of otolith function (Graybiel, 1952, 1956; Graybiel \& Clark, 1965).

Adjustments to $\mathrm{AV}$ during $\mathrm{HT}$ and $\mathrm{BT}$ resulted in the $E$-phenomenon ( $A V$ on the opposite side of GV to tilt). Means and variances for these conditions were larger than for conditions with head upright. The otolith system is involved in the Ephenomenon (Correia, Hixon, \& Niven, 1965; Miller \& Graybiel, 1966a, b; Schöne, 1964; Schöne, Parker, \& Mortag, 1967) but not to the exclusion of other systems as has been intimated (Schöne, 1964). With the head in the same position relative to gravity the E-phenomenon produced by HT is greater than that with BT, suggesting participation of proprioceptive systems in the neck and trunk.

Considering the neck system, receptors in the joint capsules of the cervical vertebrae have been shown to play an important role in maintaining spatial orientation (Cohen, 1961; McCouch, Deering, \& Ling, 1951). Malfunction of the sternomastoid muscle has also been associated with vertigo (Gray, 1956; Weeks \& Travell, 1955). Pressure receptors in the skin and viscera (Cohen, 1964; Gray \& Malcolm, 1950; Gray \& Matthews, 1951) can provide infor- mation for the orientation of the trunk relative to gravity. Mittelstaedt (1964) found normal leg and wing reflexes when tilting labyrinthless pigeons, indicating gravity receptors within the trunk. Furthermore, Clark and Graybiel (1966a) found no differences in apparent horizontality judgments by normal and labyrinthine defective Ss with head and trunk tilt relative to the resultant force direction during centrifugation. It is to be expected that these systems operate together with the otolith organs since the latter provide information for the position of the head in relation to gravity only, the neck system signals the relation of the head to the trunk which has its independent sources of orientation information.

Adjustments made with TT differ significantly from those with body upright. Under both conditions the head is in the normal vertical orientation, and therefore the otolith organs are equivalently stimulated. This effect must result from stimulation of proprioceptive systems in the neck and trunk. As with the aftereffect, the neck and trunk stimulation in TT produce effects in opposite directions, but the resultant is in the direction expected from the neck stimulation (since the effect from HT is greater than that from the opposite BT).

Visual effect and aftereffect from all tilt conditions are opposite in direction. It is probable, therefore, that the same mechanisms are involved in both. As the aftereffect following HT and BT is in the same direction as prior tilt a similar adaptation effect during tilt would be predicted, i.e., a decrease in the E-phenomenon. McFarland and Clarkson (1966) found such a decrease for $30^{\circ} \mathrm{BT}$ although they used considerably longer delays in tilt than in the present investigation. In view of the aftereffect data it is probable that the adaptation occurs mainly in the trunk proprioceptive system.

Ocular countertorsion may be involved in both the effect and aftereffect. Although countertorsion has been considered as a specific indicator of otolith function (Miller \& Graybiel, 1963) it has been found to occur with TT (Fischer, 1927). Little is known about the recovery of ocular posture following prolonged lateral tilt, and therefore its involvement in the aftereffect is speculative.

The shift in orientation constancy was greatest following prolonged HT and smallest after TT. It is suggested that this shift is induced by adaptation of the neck and trunk systems working singly or in opposition. The overconstancy that occurs during HT is greater than that during BT. It is further suggested that this is due to a greater contribution by the neck than the trunk system with, however, the otoltth system playing the major role in maintaining constancy.

A general conclusion which can be drawn from these data is that orientation constancy cannot be 
considered solely in terms of the otolith receptors. Information provided by the neck and trunk systems is also involved. When the systems mediating this information undergo change with prolonged stimulation, visual orientation is affected.

\section{References}

Aubert, H. Eine scheinbare bedeutende Drehung von Objekten bei Neigung des Kopfes nach rechts oder links, Arch. path. Anat. Physiol., 1861, 20, 381-393.

Bauemeister, M. Effect of body tilt on apparent verticality, apparent body position, and their relation. J. exp. Psychol., 1964, 67, 142-147.

Clark, B., \& Graybiel, A. Visual perception of the horizontal during prolonged exposure to radial acceleration on a centrifuge. J. exp. Psychol., 1962, 63, 294-301.

Clark, B., \& Graybiel, A. Influence of contact cues on the perception of the oculogravic illusion. BuMed. Proj. MR005. 040021.135. Pensacola, Florida, Naval School of Aviation Medicine. August 1966a.

Clark, B., \& Graybiel, A. Perception of the visual horizontal in normal and labyrinthine defective observers during prolonged rotation. Amer. J. Psychol., 1966b, 79, 608-612.

Cohen, L. A. Role of eye and neck proprioceptive mechanisms in body orientation and motor coordination. J. Neurophysiol., 1961, 24, 1-11.

Cohen, L. A. Human spatial orientation and its critical role in in space travel. Aerospace Med., 1964, 35, 1054-1057.

Correia, M. J., Hixon, W. C., \& Niven, J. I. Otolith shear and the visual perception of force direction: Discrepancies and a proposed resolution. BuMed. Proj. MR005. 13-6001. Subtask 1, Rep. No, 126. Pensacola, Florida, Naval School of Aviation Medicein. December, 1965.

Day, R. H. \& Wade, N. J. Visual spatial aftereffect from prolonged head tilt. Science, 1966, 154, 1201-1202.

Fischer, M. H. Messende Untersuchungen über die Gegenrollung der Augen und die Lokalisation der scheinbaren Vertikalen bei seitlicher Neigung (des Kopfes, des Stammes und des Gesamptkörpers). 1. Mitteilung, Neigung bìs $\mathrm{zu} 40^{\circ}$. v. Graefes Arch. Ophthal., 1927, 118, 633-680.

Fischer, M. H. Messende Untersuchungen über die Gegenrollung der Augen und die Lukalisation der scheinbaren Vertikalen bei seitlicher Neigung des Gesamptkörpers bis zu $360^{\circ}$. II. Mitteilung. Untersuchungen an Normalen. $v$. Graefes Arch. Ophthal., 1930, $123,476-508$.

Gray, L. P. Extra labyrinthine vertigo due to cervical muscle lesions. J. Laryng., 1956, 70, 353-360.

Gray, J. A. B. \& Malcolm, J. L. The initiation of nerve impulses by mesenteric Pacinian corpuscles. Proc. Roy. Soc. B., 1950 , 137, 96-114.

Gray, J. A. B., \& Matthews, P. B. C. A comparison of the adaptation of the Pacinian corpuscles with the accommodation of its axon. J. Physiol., 1951, 114, 454-464.

Graybiel, A. Oculogravic illusion. Arch Ophthal., Chicago, 1952, 48, 605-615

Graybiel, A. The importance of the otolith organs in man based upon a specific test for utricular function. Ann. Otol., 1956. $65.470-487$
Graybiel, A., \& Clark, B. Validity of the oculogravic illusion as a specific indicator of otolith function. Aerospace Med., 1965. $36,1173-1181$.

Hays, W. L. Statistics for psychologists. New York: Holt, Rinehart, \& Winston, 1964.

McCouch, G. P., Deering, I. D., \& Ling, T. H. Location of receptors for tonic neck reflexes. J. Neurophysiol., 1951, 14, 191-195.

McFarland, J. H. \& Clarkson, F. Perception of orientation: Adaptation to lateral body tilt. Amer. J. Psychol., 1966, 79, 265-271.

Mann, C. W., Berthelot-Berry, N. H., Dauterive, H. J. The perception of the vertical: 1 . Visual and non-labyrinthine cues. $J$. exp. Psychol, 1949, 39, 538-547.

Miller, E. F. Counterrolling of the human eyes produced by head tilt with respect to gravity. Acta Otolaryng., 1962, 54, 479-501.

Miller, E. F., Fregly, A. R., van den Brink, G., \& Graybiel, A. Visual localization of the horizontal as a function of body tilt up to $\pm 90^{\circ}$ from gravitational vertical. BuMed. Proi. MR005. 13-6001, Subtask 1, Rep. No. 118, Pensacola, Florida, Naval School of Aviation Medicine. August, 1965.

Miller, E. F., \& Graybiel, A. A Comparison of ocular counterrolling movements between normal subjects and deaf subjects with labyrinthine defects. Ann. Otol., 1963, 72, 885-893.

Miller, E. F., \& Graybiel, A. Role of the otolith organs in the perception of horizontality. Amer. J. Psychol., 1966a, 79, 24-37.

Miller, E. F., \& Graybiel, A. Magnitude of gravitoinertial force, an independent variable in egocentric visual localization of the horizontal. J. exp. Psychol., 1966b, 71, 452-460.

Mittelstaedt, H. Basic control patterns of orientation homeostasis, Symp, Soc, exp. Biol., 1964, 18, 365-385.

Mưller, G. E. Über das Aubertsche Phänomen. Z. Sinnesphysiol. $1916,49,109-246$.

Neal, E. Visual localization of the vertical. Amer. J, Psychol., 1926, 37, 287-291.

o'Connell, D. C., Lathrop, R. G., Weintraub, D. J., \& McHale, T. J. Apparent verticality: Psychophysical error versus sensory-tonic theory. J. exp. Psychol., 1967, 73, 347-353.

Rodger, R. S. Intermediate statistics. Sydney: University Co-operative Bookshop, 1965.

Schone, H. Über den Einfluss der Schwerkraft auf die Augenrollung und auf die Wahrnehmung der Lage im Raum. Z. vergl. Physiol. $1962,46,57-87$.

Schone, H. On the role of gravity in human spatial orientation. Aerospace Med., 1964, 35, 764-772.

Schóne, H., Parker, D. E., \& Mortag, H. G. Subjective vertical as a function of body position and gravity magnitude. Naturwis senschatten, 1967, 54, 288.

Siegel, S. Nonparanetric statistics for the behavioural sciences. New York: McGraw-Hill, 1956.

Wade, N. J., \& Day, R. H. Development and dissipation of a visual spatial aftereffect from prolonged head tilt. J. exp. Psychol., in press.

Weeks, V. D., \& Travell, J. Postural vertigo due to trigger areas in the sternocleidomastoid muscle. J. Pediat., 1955, 47, 315-327.

Winer, B. J. Statistical principles in experimental design. New York: McGraw-Hill, 1962.

\section{Note}

1. The writer would like to express appreciation to $R$. H. Day for advice and assistance.

(Accepted for publication November 3, 1967.) 